\title{
Addison's disease
}

\section{M Brosnan, N F C Gowing}

\section{Persistent vague} symptoms and hypotension should not be overlooked, as they may be the only clues to this protean disorder
St Helier Hospital, Carshalton, Surrey SM5 1AA CM Brosnan, registrar in anaesthetics

Royal Marsden Hospital, London SW3 6J J NFC Gowing, emeritus professor of pathology

Correspondence to: Dr Brosnan.

$B M \mp 1996 ; 312: 1085-7$
Primary adrenocortical insufficiency (Addison's disease) is a rare disorder in which there is destruction of the adrenal cortex, thus reducing the production of glucocorticoid, mineralocorticoid, and sex steroids. ${ }^{22}$ Most cases are now due to autoimmune disease ${ }^{3}$ and occur more often in patients with an HLA-DR3 and HLA-B8 tissue type. The disease may be associated with other immune disorders, including thyroid disease, diabetes mellitus, pernicious anaemia, hypoparathyroidism, and ovarian failure. We report two fatal cases of autoimmune Addison's disease that were diagnosed only at necropsy.

\section{Case reports} CASE 1

A 26 year old man was admitted to hospital with a history of two to three days of nausea and vomiting and increasingly frequent watery stools. $\mathrm{He}$ had also complained of a sore throat for two to three days, for which his family doctor had prescribed pivampicillin. He had not travelled overseas nor had he eaten any food outside his own home. He worked as a security officer near the Thames but never swam there. He had no previous history of weight loss, abdominal pain, or cardiovascular symptoms nor any important past medical history.

Initial examination showed him to be dehydrated with a temperature of $37.5^{\circ} \mathrm{C}$, a pulse rate of 120 beats a minute, and blood pressure of $85 / 60 \mathrm{~mm} \mathrm{Hg}$ (with no postural drop). No hyperpigmentation of skin creases or mucous membranes was noted. His tonsillar bed was inflamed. Examination of his abdomen was unremarkable. Haematological investigations gave normal results, in particular sodium $135 \mathrm{mmol} / \mathrm{l}$ (normal range $135-150 \mathrm{mmol} / \mathrm{l}$ ), potassium $5.9 \mathrm{mmol} / \mathrm{h}$ (normal range $3.5-5 \cdot 3 \mathrm{mmol} / \mathrm{l}$ ), creatinine $233 \mu \mathrm{mol} / \mathrm{h}$, urea $15.4 \mathrm{mmol} / \mathrm{l}$, and glucose $3.9 \mathrm{mmol} / \mathrm{l}$ (normal range $3 \cdot 0-8 \cdot 0 \mathrm{mmol} / \mathrm{l}$ ).

His electrocardiogram showed a sinus tachycardia with a normal axis, voltage, and T waves. A chest $x$ ray picture revealed a normal heart with normal lung fields. Urine analysis and microscopy were normal. Paracetamol and salicylate were not detected. Blood, urine, and stool cultures gave negative results, as did a monospot test and virology serology (results obtained after death). An autoantibody screen and a test for antineutrophil cytoplasmic antibodies were negative. A provisional diagnosis of viral infection complicated by acute renal failure was made. The diagnosis of Addison's disease was considered but was thought unlikely. Rehydration was started. A central venous pressure line was inserted, and renal dopamine infusion was started when his urine output was measured as less than $30 \mathrm{~m} /$ hour. An urgent abdominal ultrasound scan revealed normal kidneys and ureters and no other intra-abdominal abnormality.

Over the next few hours he became increasingly ill, with deteriorating oxygenation, and he was transferred to the intensive care unit, where he was ventilated on admission with an inspired oxygen concentration of $60 \%$ and positive end expiratory pressure of $5 \mathrm{~cm}$ water. Infusion with dobutamine $10 \mu \mathrm{g} / \mathrm{kg} / \mathrm{min}$ was also started. A pulmonary artery catheter was inserted, revealing pulmonary arterial wedge pressure of $13 \mathrm{~mm} \mathrm{Hg}$, cardiac index of $6.7 \mathrm{1} / \mathrm{min} / \mathrm{m}^{2}$, and systemic vascular resistance of $260 \mathrm{dyn} \cdot \mathrm{s}^{\cdot} \mathrm{cm}^{-5}$. Infusions of adrenaline and noradrenaline were started, as were broad spectrum antibiotics (metronidazole, benzylpenicillin, erythromycin, and cefotaxime).

He gradually deteriorated over the next 24 hours, with rising blood urea and creatinine concentrations and increasing metabolic acidosis. His cardiac index fell despite increasing ionotropic support, and electrocardiography revealed a left axis shift and the development of an intraventricular conduction defect. His creatinine kinase and alanine transferase concentrations rose to $639 \mathrm{U} / \mathrm{l}$ and $953 \mathrm{U} / \mathrm{l}$ respectively. An echocardiogram revealed acute cardiac dilatation with poor systolic function. Urgent transfer was arranged to the nearby cardiology unit. Unfortunately, just before transfer he suffered a cardiac arrest from which he could not be resuscitated.

At necropsy, the changes in most organs were nonspecific: petechial haemorrhages in the pericardium, intense acute congestion and oedema of both lungs, mild fatty change in the liver, and some swelling of the renal cortices. The heart was moderately dilated, but its weight $(340 \mathrm{~g})$ was normal. No adrenal gland tissue could be identified with certainty on macroscopic examination. Multiple blocks for histology were prepared from the adrenal sites. Microscopy revealed minute remnants of the glands infiltrated with lymphocytes (fig 1), and there were a few tiny nodules of cortical cells showing acute coagulative necrosis. There was no fibrous scarring. In view of the absence of fibrosis, the histological changes had probably developed quite rapidly. Both macroscopic and microscopic appearances were entirely different from the acute haemorrhagic destruction of the adrenal glands that occurs in some cases of septicaemia (Waterhouse-Friderichsen syndrome) and many other conditions (reviewed by $\mathrm{RaO}^{4}$ ). A random cortisol test of $30 \mathrm{nmol} / \mathrm{l}$ (result obtained after death) was consistent with the findings at necropsy.

CASE 2

A 32 year old female, who had previously enjoyed

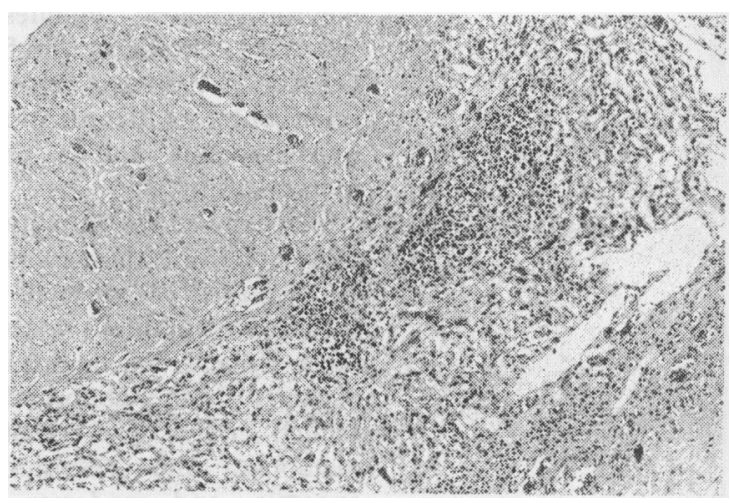

Fig 1-Low power micrograph of left adrenal from case one showing greatly thinned adrenal parenchyma between wall of central vein (top left) and part of capsule (bottom right). Cells are shrunken and are separated by oedema and lymphocyte infiltrate (haematoxylin and eosin stain) 
good health, suffered from a prolonged flu-like illness for six weeks and subsequently began to feel generally unwell. She developed generalised arthralgia and attended her local hospital over a period of nine months, and a diagnosis of inflammatory polyarthritis was made. She subsequently suffered from chest pains, severe headaches, and increasing general malaise. During this period she was not found to be hypotensive, no hyperpigmentation was ever noted, and no biochemical or electrolyte disturbances were ever detected.

Two days before her death she felt increasingly ill and developed diarrhoea and vomiting. She vomited copious amounts during the night. The family doctor was called the next morning, and he prescribed co-phenotrope after diagnosing a viral infection. The vomiting subsided and her symptoms seemed to settle, but she died suddenly at home early next day.

At necropsy, most changes were non-specific: petechial haemorrhages in the visceral pleural membranes, some acute oedema of the cerebrum with flattening of the convolutions, and multiple small haemorrhages in the gastric mucosa. Each adrenal gland was reduced to a thickness of about $2 \mathrm{~mm}$. The thyroid gland was normal in size but extremely pale, especially its right lobe. Microscopy showed almost complete destruction of the adrenocortical tissue-the residual parenchymal cells were irregular in shape with eosinophilic cytoplasm and distorted nuclei, and there was a moderate lymphocyte infiltrate (fig 2). The histological changes were interpreted as autoimmune adrenalitis (primary adrenal atrophy).

Sections of the thyroid gland showed infiltration with plasma cells and lymphocytes, lymphoid aggregates with reaction centres, reduction in the amount of colloid, and formation of Hürthle cells from the follicular cells. The histological features were those of Hashimoto's thyroiditis.

\section{Discussion}

Our two case reports represent two contrasting presentations of the same disease; the first was an acute severe illness in a previously well man, while the other was a two year history of vague symptoms in a young woman. However, both cases ended in addisonian crises, probably precipitated by viral infections.

Because the adrenal glands have a large reserve, more than $90 \%$ of the gland has to be destroyed before symptoms appear. ${ }^{5}$ Addison's disease may present with a wide range of symptoms and signs. ${ }^{6}$ These include weakness; anorexia and malaise'; hyperpigmentation (particularly of the gingival mucosa, scars, and skin creases) and vitiligo ${ }^{8}$; postural hypotension; abdominal pain; nausea, vomiting, diarrhoea, and constipation'; myalgia and arthralgia. Neuropsychiatric manifestations have also been described, including confusion, psychosis, and depression. ${ }^{10}$ Adrenal crisis is characterised by the rapid onset of hypotension, tachycardia, fever, and hypoglycaemia and a progressive deterioration in mental status. ${ }^{11}$

Biochemical abnormalities occur in $92 \%$ of patients, ${ }^{6}$ most notably hyponatraemia and hyperkalaemia with an increased (or normal) blood urea concentration. In a representative population of hospital inpatients these typical biochemical abnormalities commonly occurred. ${ }^{12}$ Other abnormalities include hypoglycaemia (which may be symptomatic), hypercalcaemia, metabolic and respiratory acidosis, normocytic anaemia, and moderate neutropenia with relative eosinophilia and lymphocytosis. ${ }^{13}$ Elevated concentrations of hepatic enzymes have also been described, and a report described three patients who were investigated for an isolated increase in serum aminotransferase

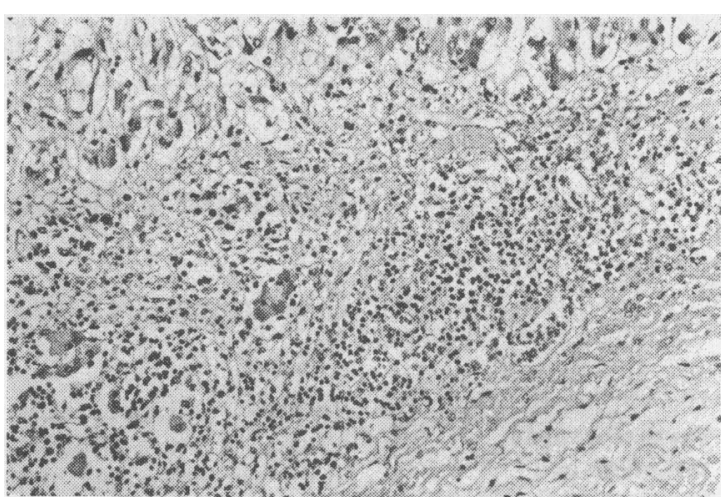

Fig 2-High power photomicrograph of left adrenal from case 2 showing small, dissociated clusters of cortical cells separated by oedema and lymphocyte infiltrate. Part of capsule is in bottom right corner (haematoxylin and eosin stain)

concentration and were found to have Addison's disease. ${ }^{14}$

The normal ranges of cortisol and adrenocorticotrophic hormone concentrations are broad. Thus, random serum samples for cortisol are unhelpful, and dynamic tests of function should be used. It has been shown that in patients with septic shock low cortisol concentrations are not uncommon and can be accompanied by loss of diurnal cortisol rhythm. ${ }^{15}$ There are, however, problems in deciding what is a "normal" response to a synacthen test in a critically ill patient, which makes diagnosing Addison's disease in such a patient much more difficult. When performing a synacthen test, it may be useful to take a basal plasma sample to measure adrenocorticotrophic hormone concentration: a plasma concentration of over $44 \mathrm{pmol} / 1$ is diagnostic. ${ }^{16}$ However, this may also be unreliable, as a study of adrenocortical function in acutely ill patients in an intensive care unit and in non-acutely ill, stressed patients found adrenocorticotrophic hormone concentrations of 9-72 $\mathrm{pmol} / 1$ and 7-141 pmol/1 respectively. ${ }^{17}$

These two cases provide several important lessons:

- Persistent vague symptoms should not be overlooked, especially in the presence of other autoimmune disorders (though antibodies are detectable in only $60-70 \%$ of patients with idiopathic disease ${ }^{18}$ )

- Hyperpigmentation is not a universal feature, especially if the cause is autoimmune (it is absent in up to $8 \%$ of patients and has led to delayed diagnoses in other cases ${ }^{19}$

- Hypotension is a common occurrence on the ITU, but persistent hypotension despite increasing ionotropic support in any patient with suspected septicaemia should raise the possibility of undiagnosed additional pathology (lack of cortisol causes a decrease in myocardial contractility, and a decreased vascular response to catecholamines ${ }^{20}$ )

- Addison's disease remains the unforgiving master of non-specificity and disguise.

We thank Mr Paul Rose, coroner, for permission to publish these cases. We also thank Drs $M$ Bending and $M$ Stockwell for permission to publish case 1, and Dr A Said for permission to publish case 2. We thank Dr Rosemary Millis for her help in preparing the photomicrographs.

1 Burke CW. Adrenocortical diseases. In: Weatherall DJ, Ledingham JGG, Warrell DA, eds. Oxford textbook of medicine. Oxford: Oxford University Press, 1983:10.58-69.

2 Neville AM. The endocrine system: the adrenal cortex. In: McGee J, Isacson P,Wright NA, eds. Oxford textbook of pathology. Oxford: Oxford University Press, 1992:1968-92.

3 Doniach D, Cudworth AG, Khoury EL, Bottazzo GF. Autoimmunity and the HLA-system in endocrine diseases. Recent Advances in Endocrinology 2;2:100-32

4 Rao RH. Massive bilateral adrenal haemorrhage. Med Clin North Am 1995;79:107-29. 
5 Liddle GW. The adrenals. Text book of endocrinology. 6th ed. Philadelphia: W B Saunders, 1981.

6 Nerup J. Addison's disease-clinical studies. A report of 108 cases. Acta Endocrinologica 1974;76:127-41.

7 Ringstad J, Rodge S, Loland W, Rode L. Rapidly fatal Addison's disease: 3 case reports. I Intern Med 1991;230:465-7.

8 Mulligan TM, Sowers JR. Hyperpigmentation, vitiligo and Addison's disease. Cutis 1985;36:317-8.

9 Tobin MV, Aldridge SA, Morris AI, Belchetz PE, Gilmore IT. Gastrointestina manifestations of Addison's disease. Am F Gastroenterol 1989;84:1302-5.

10 Varadaraj R, Cooper AJ. Addison's presenting with psychiatric symptoms. $A m$ f Psychiatry 1986;143:553-4.

11 Leshin $M$. Acute adrenal insufficiency: recognition, prevention and management. Urol Clin North Am 1982;9:229-35.

12 Paterson JR, Neithercut WD, Spooner RJ. Delayed diagnosis of Addison's disease. Ann Clin Biochem 1990;27:378-81.

13 Burke CW. Adrenocortical insufficiency. Clinics in Endocrinology and Metabolism 1985;14(4):947-76.
14 Olsson RG, Lindgren A, Zettergren L. Liver involvement in Addison's disease. Am f Gastroenterol 1989;84:1302-5.

15 Moran $\mathrm{IL}$, Chapman MJ, O'Fathartaigh MS, Peisach AR, Pannall PR, Leppard $P$. Hypocortisolaemia and adrenocortical responsiveness at onset of septic shock. Intensive Care Med 1994;20:489-95.

16 Clayton RN. Diagnosis of adrenal insufficiency. BMF 1989;298:271-2

17 Drucker D, Shandling $M$. Variable adrenocortical function in acute medical illness. Crit Care Med 1985;13:477-9.

18 Orth DN, Kovacs WJ, DeBold CR. The adrenal cortex. In: Wilson JD, Foster DW, eds. Williams textbook of endocrinology. 8th ed. Philadelphia: WB Saunders, 1992:489-619.

19 Runcie CJ, Semple CG, Slater SD. Addison's disease without pigmentation. Scott Med f 1986;31:111-2.

20 Ramey ER, Goldstein MS. The adrenal cortex and the sympathetic nervous system. Physiol Rev 1957;37:155-95.

(Accepted 18 December 1995)

\title{
Grand Rounds-Hammersmith Hospital
}

\section{Reactive (AA) systemic amyloidosis}

\author{
A cause of refractory nephrotic syndrome
}

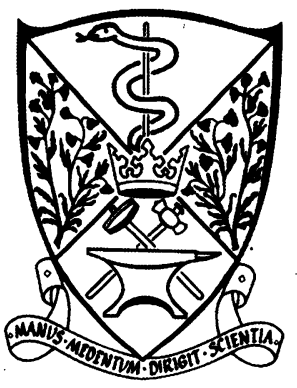

Reactive systemic (AA) amyloidosis occurs as a consequence of a prolonged acute phase response with the deposition of amyloid fibrils in various tissues. Renal involvement with the nephrotic syndrome is common, and reactive systemic amyloidosis should be considered in all patients with the nephrotic syndrome. Chronic infective foci have long been recognised as a cause of reactive systemic amyloidosis, and patients with this condition should be evaluated for occult infection. We describe such a case, in which an undetected subphrenic abscess, possibly of nine years' duration, presented with severe nephrotic syndrome.

\section{Case history}

A 49 year old woman first presented to her local hospital in 1984 with abdominal pain and haematemesis. A duodenal ulcer was diagnosed, and she was treated with $\mathrm{H}_{2}$ antagonists. An abdominal ultrasound scan showed no abnormalities. She presented again in 1989 with severe left sided abdominal pain, and a chest

Department of Medicine, Royal Postgraduate

Medical School,

Hammersmith Hospital, London W12 0NN

Case presented by:

A R Allen, registrar in

nephrology

Chairman:

$\mathrm{J}$ Scott, professor of medicine

Discussion group:

E Clutterbuck, senior lecturer in nephrology

M J Walport, professor of

rheumatology

$\mathrm{K}$ Davies, senior lecturer in rheumatology

$\mathrm{J}$ Wilding, senior registrar in endocrinology

M Thompson, consultant

histopathologist

Series edited by:

Dr W A Lynn.

$B M F$ 1996;312:1087-9

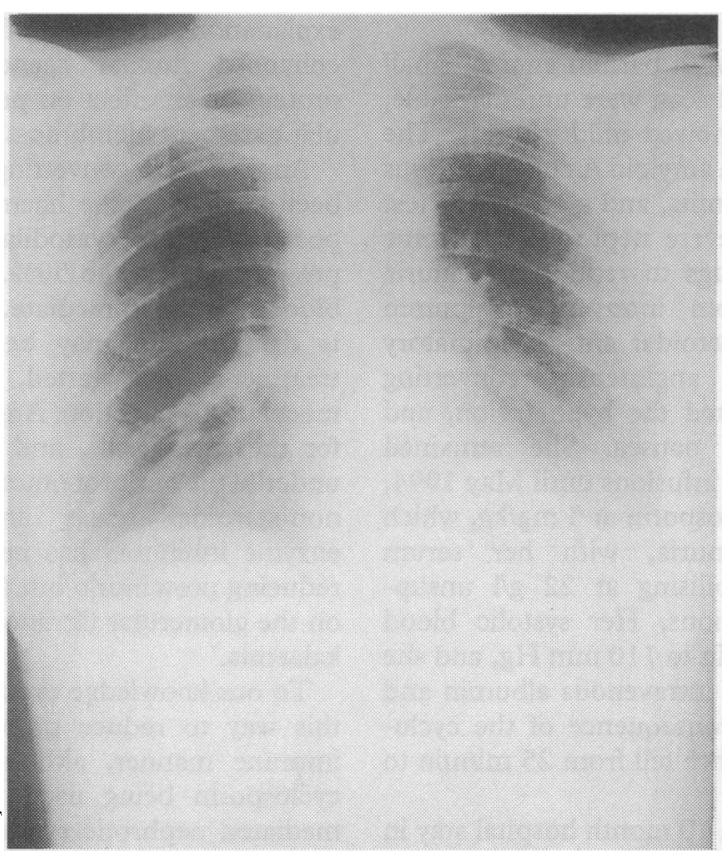

Fig 1-Chest x ray film showing raised left hemidiaphragm with patchy basal atelectasis

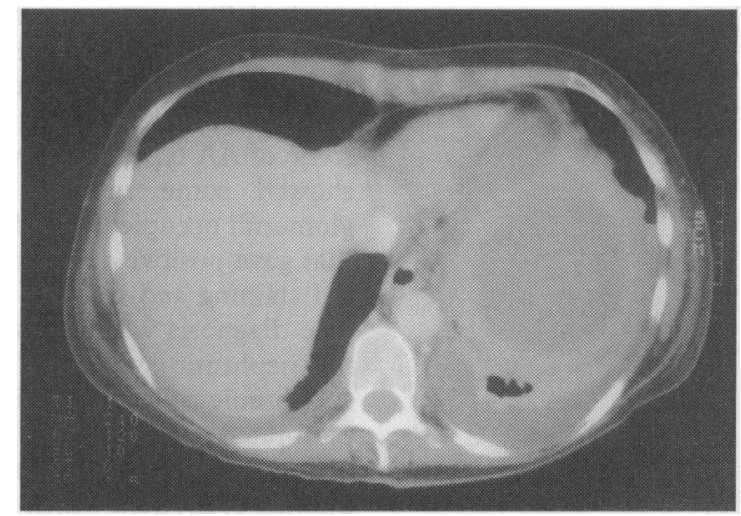

Fig 2-Abdominal computed tomogram at level of liver showing large left subdiaphragmatic collection with associated pleural effusion

$x$ ray film showed bibasal consolidation in association with serological evidence of acute mycoplasma infection. She was treated with erythromycin and recovered. (All chest $x$ ray films after this episode showed a raised left hemidiaphragm (fig 1).)

In September 1993 she was admitted with similar severe left upper quadrant pain but was now oedematous, with serum albumin concentration $11 \mathrm{~g} /$, proteinuria $5 \mathrm{~g} / 24$ hours, a creatinine clearance of $66 \mathrm{ml} / \mathrm{min}$, and an acute phase response (C reactive protein $60 \mathrm{mg} / \mathrm{l}$ (normal $<10 \mathrm{mg} / \mathrm{l}$ )). Eventually, a rectal biopsy showed the presence of amyloid, and she briefly received steroid treatment, which was of no benefit. She was transferred to this hospital in early December 1993 for further management.

On arrival she was extremely unwell with massive oedema, ascites, and bilateral pleural effusions. She was afebrile, had a blood pressure of $100 / 60 \mathrm{~mm} \mathrm{Hg}$ with a postural drop of $20 \mathrm{~mm} \mathrm{Hg}$ in systolic pressure, and was tender in the left upper quadrant. She had a serum creatinine concentration of $169 \mu \mathrm{mol} / \mathrm{h}$, creatinine clearance of $37 \mathrm{ml} / \mathrm{min}$, and serum albumin concentration of $3 \mathrm{~g} /$. She had $7.5 \mathrm{~g}$ proteinuria per 24 hours. She had received a blood transfusion to maintain her haemoglobin concentration at around $100 \mathrm{~g} / \mathrm{l}$ and still had a $\mathrm{C}$ reactive protein concentration of $117 \mathrm{mg} / \mathrm{l}$ and serum amyloid $A$ concentration of $45 \mathrm{mg} / 1$ (normal $<10 \mathrm{mg} / \mathrm{l}$ ). Blood cultures were sterile, and an abdominal computed tomogram showed a well defined left subphrenic collection of fluid (fig 2). 